OPEN ACCESS

Edited by:

Michael Deyholos,

University of British Columbia,

Canada

Reviewed by:

Fan Chen,

Institute of Genetics and

Developmental Biology (CAS), China

Ying Wang,

South China Institute of Botany (CAS),

China

*Correspondence:

Zeng-Fu Xu

zfxu@xtbg.ac.cn

Specialty section: This article was submitted to Plant Genetics and Genomics,

a section of the journa

Frontiers in Plant Science

Received: 02 September 2016

Accepted: 09 December 2016

Published: 17 January 2017

Citation:

Chen M-S, Pan B-Z, Fu Q, Tao Y-B, Martínez-Herrera J, Niu L, Ni J,

Dong $Y$, Zhao $M-L$ and $X U$ Z-F (2017) Comparative Transcriptome

Analysis between Gynoecious and Monoecious Plants Identifies Regulatory Networks Controlling Sex

Determination in Jatropha curcas.

Front. Plant Sci. 7:1953.

doi: 10.3389/fpls.2016.01953

\section{Comparative Transcriptome Analysis between Gynoecious and Monoecious Plants Identifies Regulatory Networks Controlling Sex Determination in Jatropha curcas}

\author{
Mao-Sheng Chen', Bang-Zhen Pan', Qiantang Fu', Yan-Bin Tao', \\ Jorge Martínez-Herrera ${ }^{2}$, Longjian Niu' ${ }^{1}$, Jun Ni' ${ }^{1}$, Yuling Dong ${ }^{1}$, Mei-Li Zhao ${ }^{1}$ and \\ Zeng-Fu Xu'*
}

\footnotetext{
' Key Laboratory of Tropical Plant Resources and Sustainable Use, Xishuangbanna Tropical Botanical Garden, Chinese Academy of Sciences, Menglun, China, ${ }^{2}$ Instituto Nacional de Investigaciones Forestales, Agrícolas y Pecuarias, Huimanguillo, Mexico
}

Most germplasms of the biofuel plant Jatropha curcas are monoecious. A gynoecious genotype of $\mathrm{J}$. curcas was found, whose male flowers are aborted at early stage of inflorescence development. To investigate the regulatory mechanism of transition from monoecious to gynoecious plants, a comparative transcriptome analysis between gynoecious and monoecious inflorescences were performed. A total of 3,749 genes differentially expressed in two developmental stages of inflorescences were identified. Among them, 32 genes were involved in floral development, and 70 in phytohormone biosynthesis and signaling pathways. Six genes homologous to KNOTTED1-LIKE HOMEOBOX GENE 6 (KNAT6), MYC2, SHI-RELATED SEQUENCE 5 (SRS5), SHORT VEGETATIVE PHASE (SVP), TERMINAL FLOWER 1 (TFL1), and TASSELSEED2 (TS2), which control floral development, were considered as candidate regulators that may be involved in sex differentiation in J. curcas. Abscisic acid, auxin, gibberellin, and jasmonate biosynthesis were lower, whereas cytokinin biosynthesis was higher in gynoecious than that in monoecious inflorescences. Moreover, the exogenous application of gibberellic acid $\left(\mathrm{GA}_{3}\right)$ promoted perianth development in male flowers and partly prevented pistil development in female flowers to generate neutral flowers in gynoecious inflorescences. The arrest of stamen primordium at early development stage probably causes the abortion of male flowers to generate gynoecious individuals. These results suggest that some floral development genes and phytohormone signaling pathways orchestrate the process of sex determination in J. curcas. Our study provides a basic framework for the regulation networks of sex determination in J. curcas and will be helpful for elucidating the evolution of the plant reproductive system.

\footnotetext{
Keywords: female plant, floral development, inflorescence, physic nut, phytohormone, sex expression
} 


\section{INTRODUCTION}

Flowering plants show extreme diversity in their reproductive systems. The determination of the environmental and genetic factors that control sexual diversification is a central problem in plant evolutionary biology (Barrett, 2002). Plant sex determination that leads to the physical separation of male and female reproductive organs plays a crucial role in the evolutionary process from hermaphroditic to unisexual flowers (Dellaporta and Calderon-Urrea, 1993; Tanurdzic and Banks, 2004). In order to facilitate outcrossing and more efficient allocation of resources to optimization of reproduction (Bawa, 1980; Thomson and Barrett, 1981), approximately $10 \%$ of angiosperm species have produced unisexual flower reproductive systems in dioecious and monoecious plant taxa (Yampolsky and Yampolsky, 1922). Genetic, hormonal, and environmental cues are involved in the regulation of sex determination in flowering plants (Aryal and Ming, 2014). Sex determination has evolved multiple times independently suggesting that various different genetic mechanisms underlie unisexual flower development (Ainsworth et al., 1998; Chuck, 2010; Diggle et al., 2011).

In cucumber, sex determination is controlled by three genetic loci: $F, A$, and $M$. The $F$ locus controls the degree of femaleness, the $A$ locus increases maleness and the $M$ locus is responsible for the selective abortion of stamens (Pierce and Wehner, 1990; PerlTreves, 1999). The $F$ locus is linked to the 1-aminocyclopropane-1 carboxylic acid synthase (ACS) gene encoding the rate-limiting enzyme in ethylene (ETH) biosynthesis, which is present as a single copy in monoecious lines but as a duplicated copy in gynoecious lines (Kamachi et al., 1997; Mibus and Tatlioglu, 2004). The $M$ locus encodes the CsACS2 gene, in which a conserved residue conversion (Gly33Cys) causes bisexual flower production (Li et al., 2009). The ETH receptor ETR1 is suppressed, causing female flower generation in Arabidopsis, suggesting that ETH perception is involved in stamen abortion (Wang et al., 2010). Sex determination in melon is controlled by two loci, andromonoecious (a) and gynoecious ( $g$ ) (Poole and Grimball, 1939), and their interaction results in a range of sexual types (Kenigsbuch and Cohen, 1990). The $a$ locus is linked to the GmACS-7 gene, in which a single missense mutation causes loss of enzymatic activity, resulting in the development of male organs to generate andromonoecious plants (Boualem et al., 2008). CmACS-7 mainly represses stamen development and is not required for carpel development, although CmACS7 is expressed in the carpel primordia during melon flower development (Boualem et al., 2008). The $g$ locus is links to a transcription factor, CmWIP1, which is a repressor of carpel development. The activation of CmWIP1 by promoter methylation results in the transition from male to female flowers in gynoecious plants (Martin et al., 2009). CmACS-11, encoding a key enzyme of ETH biosynthesis, represses CmWIP1 expression, and CmACS-11 loss-of-function mutation lead to the transition from monoecious to androecious individuals (Boualem et al., 2015). CmACS-11, CmWIP1, and CmACS-7 coregulate sex determination in melon. In maize, seven mutants affecting male flower (tassel) development have been identified, including six tasselseed mutants and one nal mutant (Zhang J. et al., 2014). tasselseed1 (ts1) encodes a lipoxygensae involved in jasmonic acid (JA) biosynthesis. Loss of functional ts1 causes a decrease in endogenous JA concentrations in developing inflorescences, and exogenous JA can rescue stamen development in ts1 mutants (Acosta et al., 2009). tasselseed2 (ts2) encodes a short-chain alcohol dehydrogenase, required for the arrest of pistil primordia development in the maize tassel (DeLong et al., 1993). tasselseed4 (ts4) encodes a miR172 microRNA targeting tasselseed6 (ts6)/indeterminate spikelet1 (ids1), which is an APETALA2 (AP2)-like gene. ts4 and $i d s 1$ are required for the carpel abortion in the tassel (Chuck et al., 2007). nana plant1 ( $\mathrm{na}$ ) encodes a $5 \alpha$-steroid reductase involved in brassinosteroid (BR) biosynthesis, and a mutation of nal causes a decrease in BR metabolites, leading to dwarf and feminizing phenotypes (Hartwig et al., 2011). In addition, anther ear (an1), $d$ warf1 $(d 1), d 2, d 3, d 5$, and $d 8$ mutants, which are deficient in gibberellic acid (GA) biosynthesis or perception, produce perfect florets in the tassel (Dellaporta and Calderon-Urrea, 1994), and GA application to an 1 converts male to gynoecious florets in the tassel (Bensen et al., 1995), indicating that GA is a negative regulator during stamen development in maize (Tanurdzic and Banks, 2004; Chen and Tan, 2015). However, GA is a positive regulator in the development of stamens and pollen in Arabidopsis and rice (Cheng et al., 2004) and is considered to exert masculine effects in plant sex expression (Aryal and Ming, 2014). In Diospyros, the autosomal MeGI (Japanese for "female tree") is a feminizing gene controlling anther fertility in a dosage-dependent fashion. A Y-chromosome OGI (Japanese for "male tree") encoding a small RNA suppresses MeGI expression, resulting in the generation of androecious individuals (Akagi et al., 2014). These results suggest that at least three different regulation mechanisms of sex determination are present in flowering plants.

The exogenous application of auxin, BR, cytokinin (CK), ETH, GA, JA, and their inhibitors affects sex expression in flowering plants (Louis and Durand, 1978; Chailakhyan, 1979; Durand and Durand, 1984; Irish and Nelson, 1989; Perl-Treves, 1999), and some of them have opposing effects on sex determination in different plant lineages (Yamasaki et al., 2005). Environmental cues such as temperature, photoperiod, nutrition, drought, $\mathrm{pH}$, and seasonality also effect sex determination in many species (Korpelainen, 1998; Field et al., 2013; Golenberg and West, 2013). However, the mechanism of environmental sex determination remains largely unknown, and epigenetic mechanisms are likely involved in the process (Piferrer, 2013).

Jatropha curcas L. is known as a potential biofuel plant, owing to its high seed oil content (Fairless, 2007; Sato et al., 2011). Most J. curcas germplasms are monoecious (Rincon-Rabanales et al., 2016), bearing male and female flowers on the same inflorescence. Low female:male flower ratio of approximately 1:13-29 in monoecious plants has been considered to be one of the factors causing low seed yield in J. curcas (Pan and $\mathrm{Xu}, 2011)$. Therefore, it is crucial to improve the female flower number per inflorescence for the increase in J. curcas seed yield. Previous research showed that the exogenous application of CK (6-benzyladenine, BA) on inflorescence buds significantly increases the female flower number and female:male flower ratio, 


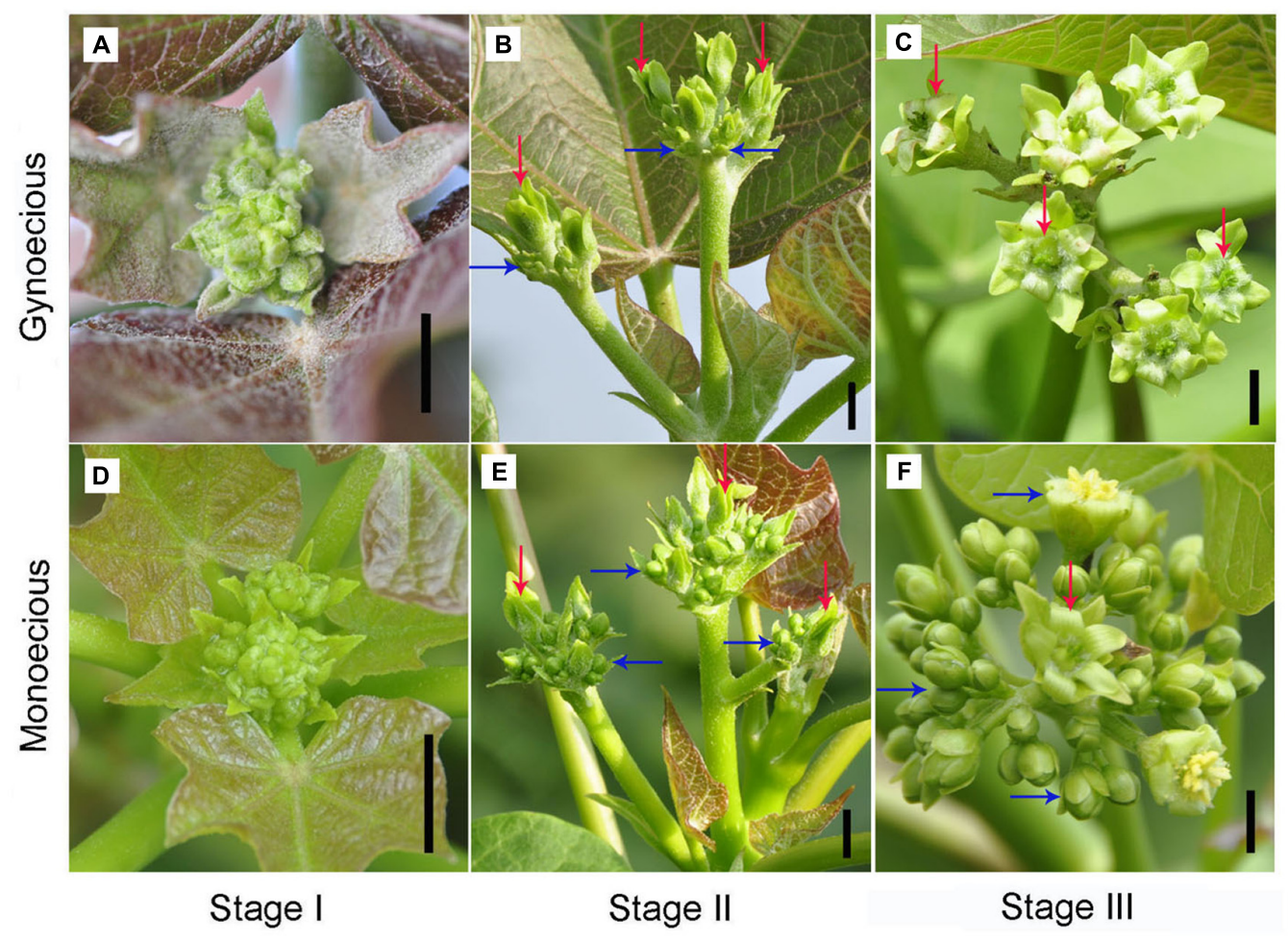

FIGURE 1 | Morphological comparison of inflorescences between gynoecious and monoecious plants at different developmental stages. (A-C) Indicate gynoecious inflorescences at stages I, II, and III, respectively. (D-F) Indicate monoecious inflorescences at stages I, II, and III. Stage I spans approximately 1-7 days from the formation of visible inflorescence buds in which female and male flowers are normally develop in gynoecious plants. Stage II spans approximately 8-20 days from the formation of visible inflorescence buds in which female flowers are normally develop and male flowers are arrest in gynoecious plants. Stage III spans approximately 21-30 days from the formation of visible inflorescence buds in which gynoecious inflorescences have blooming female flowers. Red arrows indicate female flowers and blue arrows indicate male flowers; bar, $0.5 \mathrm{~cm}$.

resulting in an increase in seed yield (Pan and $\mathrm{Xu}, 2011$; Chen et al., 2014; Fröschle et al., 2016). These results suggest that CKs are involved in Jatropha sex differentiation. In this study, a gynoecious genotype of J. curcas, whose male flowers are aborted at early stage of inflorescence development, was used for a comparative transcriptome analysis between gynoecious and monoecious inflorescences, to identify the regulation networks that participate in sex differentiation of J. curcas. The findings of this study will be helpful in understanding the sex determination mechanism in J. curcas.

\section{MATERIALS AND METHODS}

\section{Application of Gibberellin (GA) and Collection of Samples for RNA Isolation}

Gynoecious and monoecious plants were grown in the field in the Xishuangbanna Tropical Botanical Garden of the Chinese Academy of Sciences, located in Menglun town in Mengla County $\left(21^{\circ} \mathrm{N}, 101^{\circ} \mathrm{E}\right)$, Yunnan province, China. Gynoecious inflorescence buds that occurred about 1-7 days were treated with $1.5 \mathrm{mM} \mathrm{GA}_{3}$ solution. Inflorescence buds that occurred about 3-4 days (stage I) and 8-9 days (stage II) were harvested from gynoecious and monoecious plants, respectively, for
RNA isolation (Figure 1). Three biological replications were performed for each sample group. Morphologies of female and male flowers at developmental stages I and II were observed by a 3D super depth digital microscope (ZEISS Smartzoom 5).

\section{RNA Isolation and Transcriptome Sequencing}

Total RNA was extracted from inflorescences using the plant total RNA extraction reagent pBIOZOL (Bioflux, Germany). RNA purity was checked with a NanoPhotometer spectrophotometer (IMPLEN, Westlake Village, CA, USA). RNA concentration was determined with a Qubit 2.0 Fluorometer (Life Technologies, Carlsbad, CA, USA). RNA integrity was assessed with an Agilent Bioanalyzer 2100 system (Agilent Technologies, Santa Clara, CA, USA). Sequencing libraries were prepared with a NEBNext Ultra RNA Library Prep Kit for Illumina (NEB, USA) following the manufacturer's specifications. Library quality was assessed on the Agilent Bioanalyzer 2100 system. The clustering of the index-coded samples was performed on a cBot Cluster Generation System according to the manufacturer's instructions. After cluster generation, the libraries were sequenced on an Illumina HiSeq 2500 platform and 125-base paired-end reads were produced. Sequencing was 
performed by Novogene Bioinformatics Technology (Beijing, China).

\section{De novo Transcriptome Assembly and Abundance Estimation}

Low-quality (with $<20$ Phred scores) reads in raw reads were removed with Fastq_clean (Zhang M. et al., 2014) and assessed with FASTQC ${ }^{1}$. Clean reads were assembled using Trinity (version 2.0.6) with default parameters (Grabherr et al., 2011; Haas et al., 2013). The paired-end reads from each library were mapped to the de novo assemblies using Bowtie (version 1.1.1) (Langmead et al., 2009), and abundance estimation of transcripts was performed using Corset (version 1.03) (Davidson and Oshlack, 2014).

\section{Identification of Differentially Expressed Transcripts}

Cluster-level count data generated from Corset were processed with the edgeR package (Robinson et al., 2010). Very low-count transcripts were removed and transcripts with at least one count per million reads (CPM) in at least three libraries were kept for analysis. A design matrix fitting generalized linear models (GLMs) was constructed and the Cox-Reid profile-adjusted likelihood (CR) method was used to estimate common, trended, and tagwise dispersions. Differential expressed transcripts were determined using GLM likelihood ratio test and transcripts with a false discovery rate (FDR) of $<0.001$ were reported for annotation analysis. A Venn diagram of differentially expressed genes was generated using Venny diagrams ${ }^{2}$.

\section{Transcript Annotation and Clustering Analysis}

Gene Ontology (GO) classification and enrichment analysis were performed with DAVID (Huang et al., 2009). Hierarchical clustering of genes was performed using the pheatmap R package (version 1.0.7) ${ }^{3}$.

\section{Real Time Quantitative PCR (qPCR)}

Total RNA was extracted using the plant total RNA extraction reagent pBIOZOL (Bioflux, Germany). For each sample, total RNA $(1 \mu \mathrm{g})$ was used for cDNA synthesis using PrimeScript kit (Takara Biotechnology, China). qPCR was performed on Roche Light Cycler 480II system (Roche) using LightCycler FastStart DNA MasterPLUS SYBR Green I Kit (Roche). Each sample has two or three biological replicates. Primers used for qPCR analysis were listed in Supplementary Table S7.

\section{Availability of Supporting Data}

All RNA-Seq data for this project have been deposited in NCBI under the SRA accession SRP092157. For simplicity, only sequences of genes that appeared in the context of this paper are listed in Supplementary Data Sheet 1.

\footnotetext{
${ }^{1}$ http://www.bioinformatics.babraham.ac.uk/projects/fastqc

${ }^{2}$ http://bioinfogp.cnb.csic.es/tools/venny/index.html

${ }^{3}$ https://github.com/cran/pheatmap
}

\section{RESULTS}

\section{Morphological Comparison between Gynoecious and Monoecious Plants}

To facilitate comparative research on inflorescence development between gynoecious and monoecious plants, the process of inflorescence development was roughly classified into three stages on the basis of inflorescence morphology. In stage I, spanning 1-7 days from the formation of visible inflorescence buds, both female and male flowers could develop in gynoecious plants that is similar to the monoecious plants (Figure 1). In this stage, 10 stamen primordia were found in an inner-outer whorl arrangement in male flowers, and three carpel primordia emerged in female flowers in both gynoecious and monoecious plants (Figure 2). Interestingly, stamen primordia also presented in monoecious female flowers, but were invisible in gynoecious ones (Figure 2). In stage II, spanning 8-20 days, the development of male flowers in gynoecious plants was clearly arrested and stamen primordia turned brown, whereas in monoecious male flowers stamen primordia developed into anthers (Figures 1 and 2). In this stage, carpels closed up to develop into ovaries, and nectaries were formed in both gynoecious and monoecious female flowers; stamen primordia in monoecious female flowers were degenerated (Figure 2). In stage III, spanning 21-30 days, gynoecious inflorescences had blooming female flowers and vestigial male flowers, whereas monoecious inflorescences consisted of normal female and male flowers (Figure 1). Moreover, leaves of gynoecious plants were larger than ones of monoecious plants; gynoecious fruits were spindle-shaped, whereas monoecious fruits are round, but their seeds are similar in size and shape (Supplementary Figures S1 and S2).

\section{Identification of Differentially Expressed Genes}

To investigate the mechanism of sex determination in J. curcas, we collected four groups of samples containing monoecious inflorescences at stages I and II ( $\mathrm{mI}$ and $\mathrm{mII}$ ) and gynoecious inflorescences at stages I and II (gI and gII) for RNA-Seq analysis to identify differentially expressed genes that might be involved in the transition between monoecy and gynoecy (Supplementary Table S1). A plot that shows the relationship between the four groups of samples based on multidimensional scaling with the biological coefficient of variation, displays that gynoecious and monoecious samples are well separated, indicating the presence of large numbers of differentially expressed genes (Figure 3). For simplicity, we will hereafter refer to the comparison of stage II vs. stage I in monoecious inflorescences as the pairwise mII vs. mI, the stage II vs. I in gynoecious inflorescences as pairwise gII vs. gI, the gynoecious vs. monoecious inflorescence at stage I as pairwise gI vs. mI, and the gynoecious vs. monoecious inflorescence at stage II as pairwise gII vs. mII. In all, 3,707 genes were significantly changed at an FDR of $<0.001$ in four pairs (Supplementary Table S2). In pairwise mII vs. mI, only three differentially expressed 


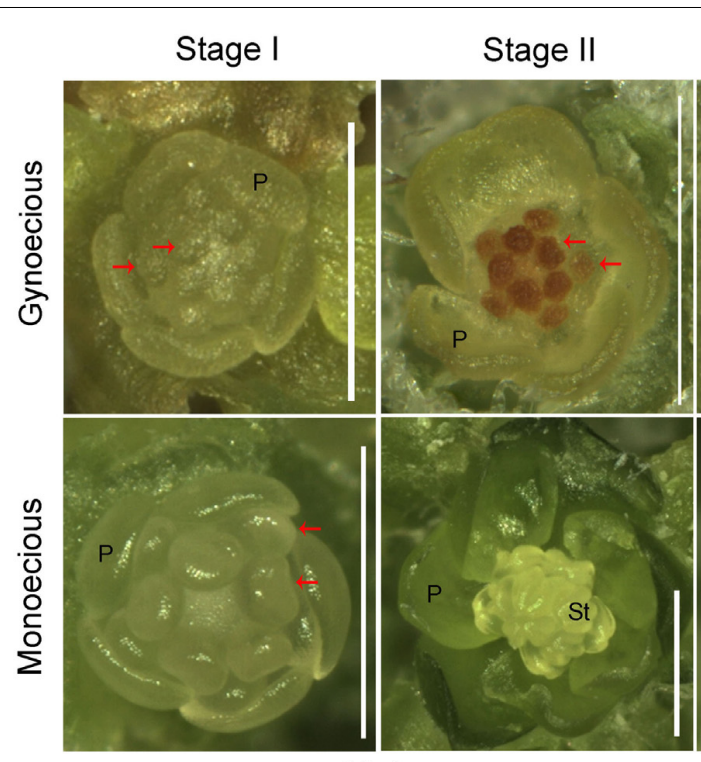

Male

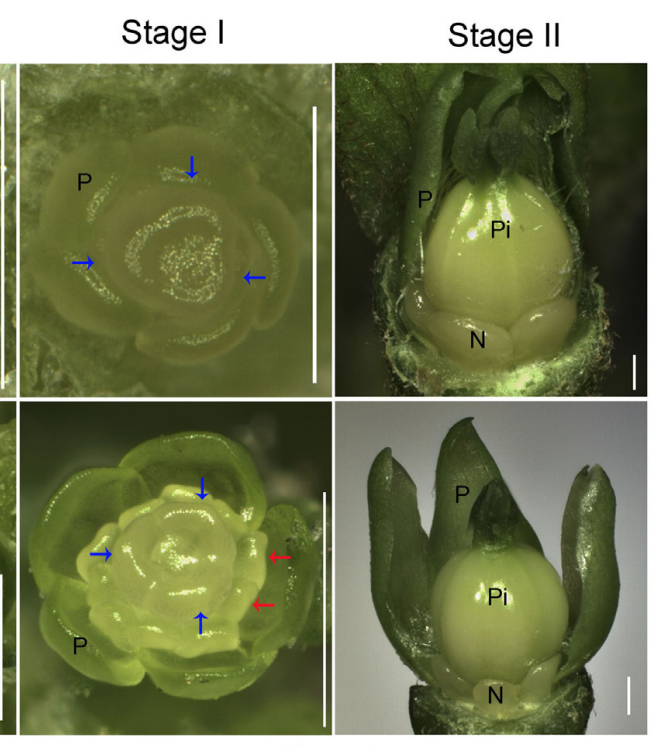

Female

FIGURE 2 | Morphological comparison of female and male flowers between gynoecious and monoecious plants at developmental stages I and II. P, petal; St, stamen; Pi, pistil; N, nectary; red and blue arrows indicate stamen and carpel primordia, respectively; bar, $0.5 \mathrm{~mm}$.

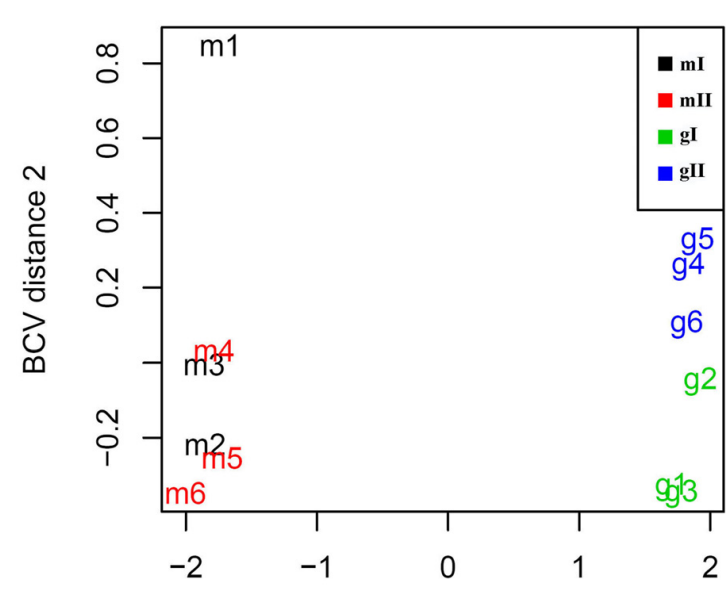

BCV distance 1

FIGURE 3 | Relationships between 12 inflorescence samples based on multidimensional scaling. In the plot, dimension 1 clearly separates monoecious and gynoecious samples. Dimension 2 unambiguously separates two different developmental phase samples in gynoecious plants, whereas two group monoecious samples cannot be clearly separated. $\mathrm{ml}$ containing $\mathrm{m} 1, \mathrm{~m} 2$, and $\mathrm{m} 3$, indicates monoecious samples at stage I; mll containing $\mathrm{m} 4, \mathrm{~m} 5$, and $\mathrm{m} 6$, indicates monoecious samples at stage II; gl containing g1, g2, and g3, indicates gynoecious samples at stage I; gll containing g4, g5, and g6, indicates gynoecious samples at stage II. BCV, biological coefficient of variation.

genes were upregulated and 28 were downregulated, whereas 492 were upregulated and 759 were downregulated in pairwise gII vs. gI (Figure 4). In pairwise gI vs. mI, 1,037 genes were upregulated and 630 were downregulated, whereas 1,560 were upregulated and 1,072 were downregulated in pairwise gII vs. gI (Figure 4).

The above results show that significantly more differentially expressed genes were found during inflorescence development from stage I to II in gynoecious plants than ones in monoecious plants, indicating that a very different physiological and biochemical process was occurring during this developmental transition between these two genotypes. Considering that the morphological differences between gynoecious and monoecious plants were mainly resulted from the arrest of stamen primordia that initiates at stage I (Figure 2) and the abortion of male flowers that occurs from stage I to stage II in gynoecious plants (Figure 1), we focused on the 171 coexpressed genes in pairwise gI vs. $\mathrm{mI}$ and gII vs. gI, excluding the 47 coexpressed genes in pairwise gII vs. gI, gI vs. $\mathrm{mI}$ and gII vs. mII (Figure 5) because these differentially expressed genes in pairwise gII vs. mII might be a consequence rather than a cause of stamen primordia arrest. GO analysis shows that the 171 coexpressed genes belong to 25 subset GO categories, and the "Membrane," "Regulation of biological process," "Regulation of cellular process," and "Ion binding" functional categories are predominant (Figure 6; Supplementary Table S3). The genes associated with reproductive (GO:0022414), reproductive developmental (GO:0003006), and developmental regulation (GO:0050793) processes are likely to play important roles during male flower abortion in gynoecious Jatropha.

\section{Differentially Expressed Genes Related to Floral Development}

Owing to that differentially expressed genes associated with the "Reproductive process" and "Reproductive 


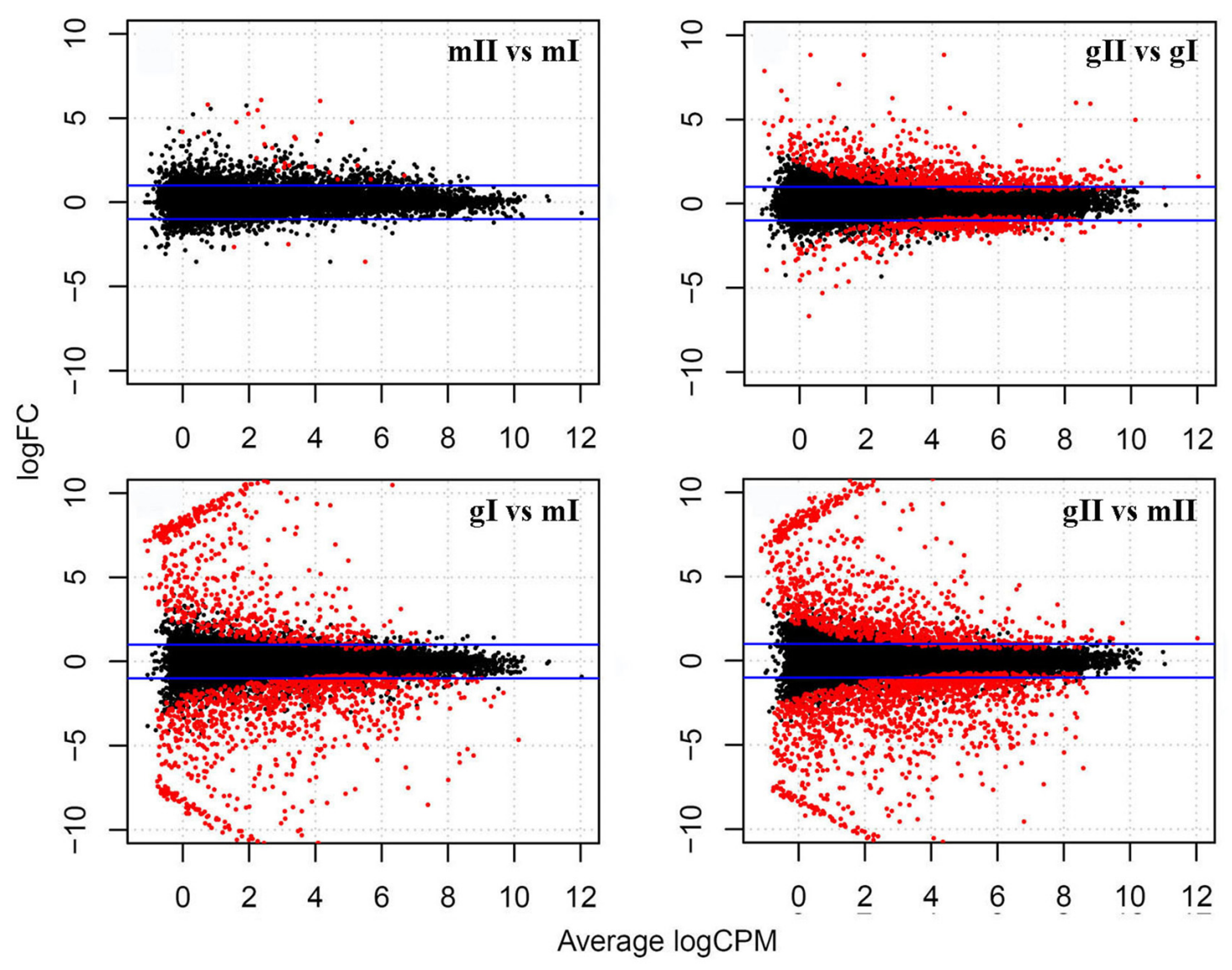

FIGURE 4 | Differentially expressed genes in the pairwise mll vs. $\mathrm{ml}$, gll vs. gl, gl vs. $\mathrm{ml}$ and gll vs. $\mathrm{mll}$ in J. curcas. $\mathrm{mll}$ vs. $\mathrm{ml}$ indicates the pairwise stage II vs. I in monoecious inflorescences; gll vs. gl indicates the stage II vs. I in gynoecious inflorescences; gl vs. ml indicates the gynoecious vs. monoecious inflorescences at stage I and gll vs. $\mathbf{m l l}$ indicates the gynoecious vs. monoecious inflorescences at stage II. Blue lines indicate genes with a twofold change; red points indicate genes with a significantly different expression at a false discovery rate (FDR) of <0.001. FC, fold change; CPM, counts per million mapped reads.

developmental process" functional categories are enriched $(P<0.05)$, we accordingly scanned our assembled data set and identified 32 genes that are homologous to floral development genes in model plants such as Arabidopsis, maize, and melon (Supplementary Table S4). In pairwise $\mathrm{mII}$ vs. $\mathrm{mI}, 11$ genes were upregulated and 2 were downregulated, whereas 8 were upregulated and 11 were downregulated in pairwise gII vs. gI (Fold change $\geq 2.0$ and FDR $<0.05$ ) (Figure 7; Supplementary Table S5). AGAMOUS (AG), APETALA3 (AP3), SHATTERPROOF 1 (SHP1), SPOROCYTELESS (SPL), SEEDSTICK (STK), FLOWERING LOCUS D (FD), and UNUSUAL FLORAL ORGANS (UFO) have similar expression patterns in pairwise $\mathrm{mII}$ vs. $\mathrm{mI}$ and gII vs. gI, suggesting that the changes in transcriptional levels may be caused by different development stages. In pairwise gI vs. mI, six genes were upregulated and three were downregulated, whereas six were upregulated and 16 were downregulated in pairwise gII vs. mII (Figure 7; Supplementary Table S5).

\section{Differentially Expressed Genes Involved in Phytohormone Biosynthesis and Signaling Pathways}

Phytohormones play an important part in the process of sex expression (Aryal and Ming, 2014), we monitored homologous genes involved in hormone metabolism and signaling pathways during the inflorescence development of J. curcas. In all, 70 differentially expressed genes were identified, in which eight were from abscisic acid (ABA), 16 from auxin, 9 from BR, 11 from CK, 4 from ETH, 7 from GA, 8 from JA, and 7 from salicylic acid (SA) pathways (Supplementary Table S6). Among them, some genes encoding key rate-limiting enzymes in hormone biosynthesis pathways were significantly changed. In pairwise gII vs. gI and gII vs. mII, the expression of NINE-CIS-EPOXYCAROTENOID DIOXYGENASES 3 (NCED) and NCED5 in ABA biosynthesis, TRYPTOPHAN AMINOTRANSFERASE OF ARABIDOPSIS 1 (TAA1) and YUCCA (YUC) in auxin, 1-AMINOCYCLOPROPANE-1CARBOXYLIC ACID SYNTHASE (CmACS-7) in ETH, GA 20-oxidase 2 (GA20ox2) and GA 3-oxidase 1 (GA3ox1) in GA, 


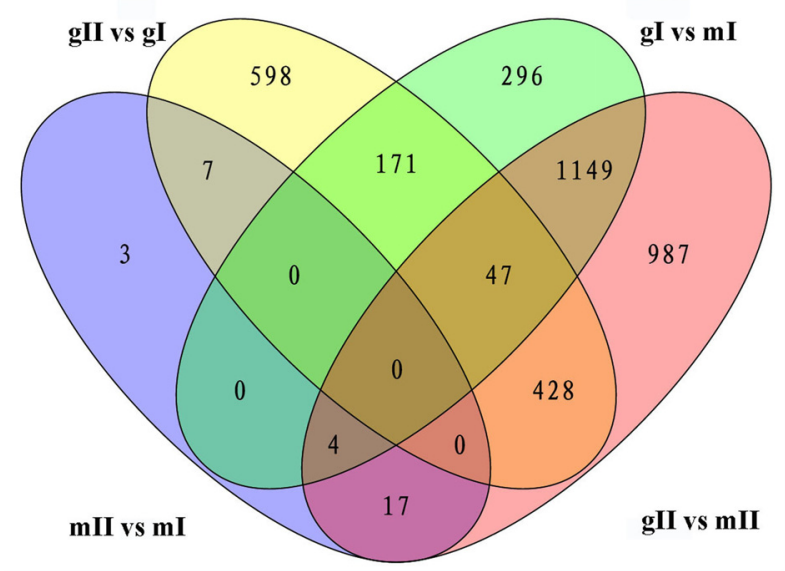

FIGURE 5 | Venn diagram shows the overlap of differentially expressed genes in the pairwise $\mathrm{mll}$ vs. $\mathrm{ml}$, gll vs. gl, $\mathrm{gl}$ vs. $\mathrm{ml}$, and gll vs. $\mathrm{mll}$ in J. curcas. mll vs. ml, gll vs. gl, gl vs. $\mathrm{ml}$, and gll vs. mll indicate the same pairs as shown in Figure 4.
DEFECTIVE ANTHER DEHISCENCE 1 (DAD1), FATTY ACID DESATURASE 8 (FAD8), LIPOXYGENASE 2 (LOX2), ALLENE OXIDE SYNTHASE (AOS), and ALLENE OXIDE CYCLASE 3 (AOC3) in JA were downregulated, whereas ATP/ADP isopentenyltransferases 5 (IPT5), CYP735A1, and LONELY GUY 5 (LOG5) in CK were upregulated (Figure 8).

\section{Validation of the Expression Profiles of Candidate Genes Involved in Sex Determination of $J$. curcas by Real Time qPCR}

To validate the expression profiles of candidate genes obtained from the above comparative transcriptome analysis, we selected 10 candidate genes involved in sex determination of J. curcas to perform real time qPCR analysis. These 10 genes are AOS, DAD1, KNOTTED1-LIKE HOMEOBOX GENE 6 (KNAT6), MYC2, SHIRELATED SEQUENCE 5 (SRS5), SHORT VEGETATIVE PHASE (SVP), TAA1, TERMINAL FLOWER 1 (TFL1), TASSELSEED2 (TS2) and YUCCA 4 (YUC4). The results revealed by real time qPCR (Figure 9) show that the expression patterns of these genes were consistent with the ones obtained by transcriptome analysis (Figure 7; Supplementary Tables S4 and S5), indicating transcriptome data in this study are reliable.

\section{Effect of GA on Flower Organ Development in Gynoecious Plants}

Since the expression of two GA biosynthesis genes GA20ox2 and GA3ox1 was found downregulated in gynoecious inflorescence (Figure 8; Supplementary Table S6), we investigated the effect of GA on flower organ development in gynoecious plants. The result showed that exogenous application of $\mathrm{GA}_{3}$ promoted perianth development in male flowers and partly prevented pistil development in female flowers in gynoecious plants,

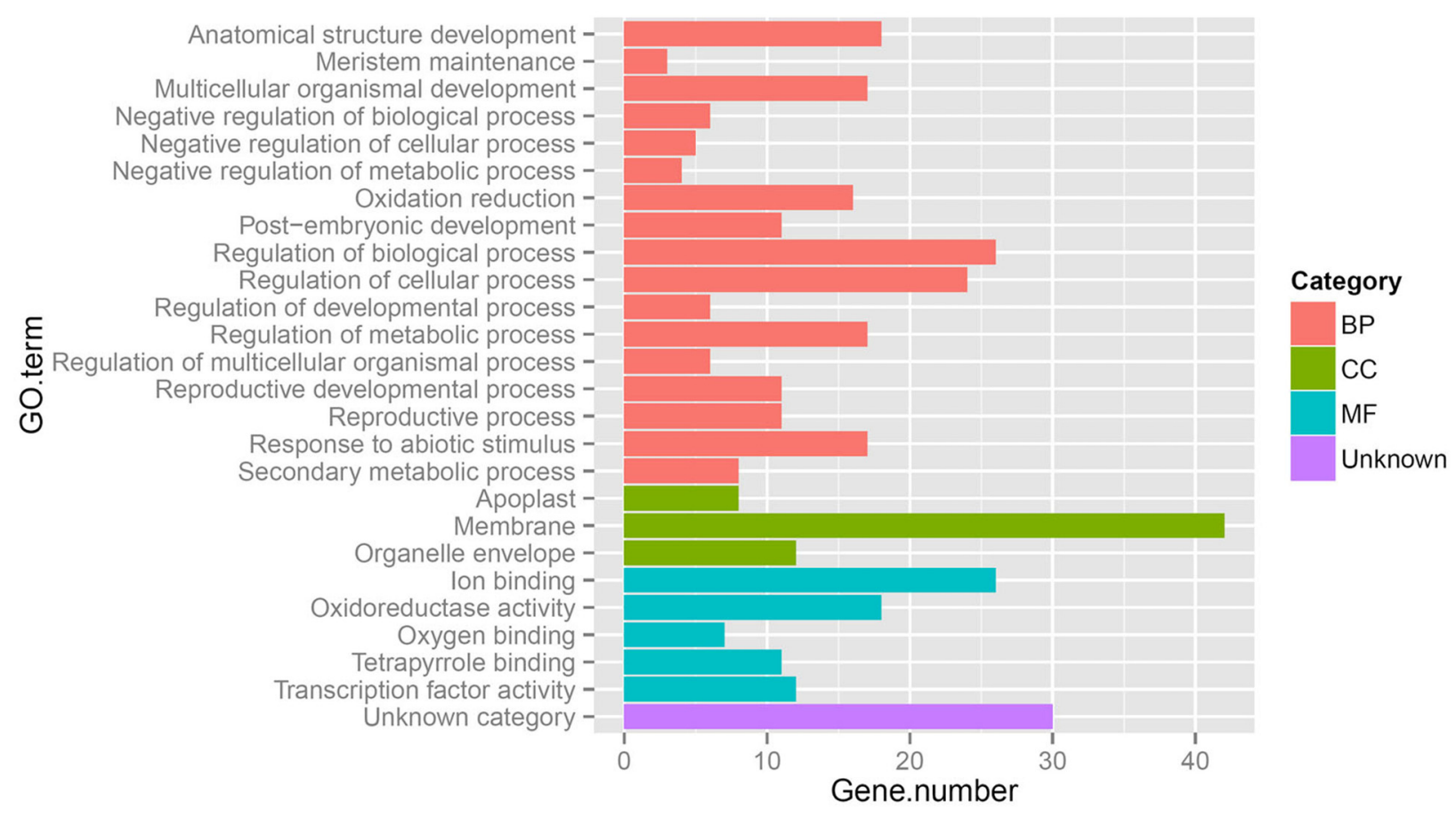

FIGURE 6 | Gene Ontology (GO) categories of 171 coexpression genes in the pairwise gll vs. gl and gl vs. $\mathbf{m l}$. BP, biological process; CC, cellular component; MF, molecular function. gll vs. gl and gl vs. $\mathrm{ml}$ indicate the same pairs as shown in Figure 4. 


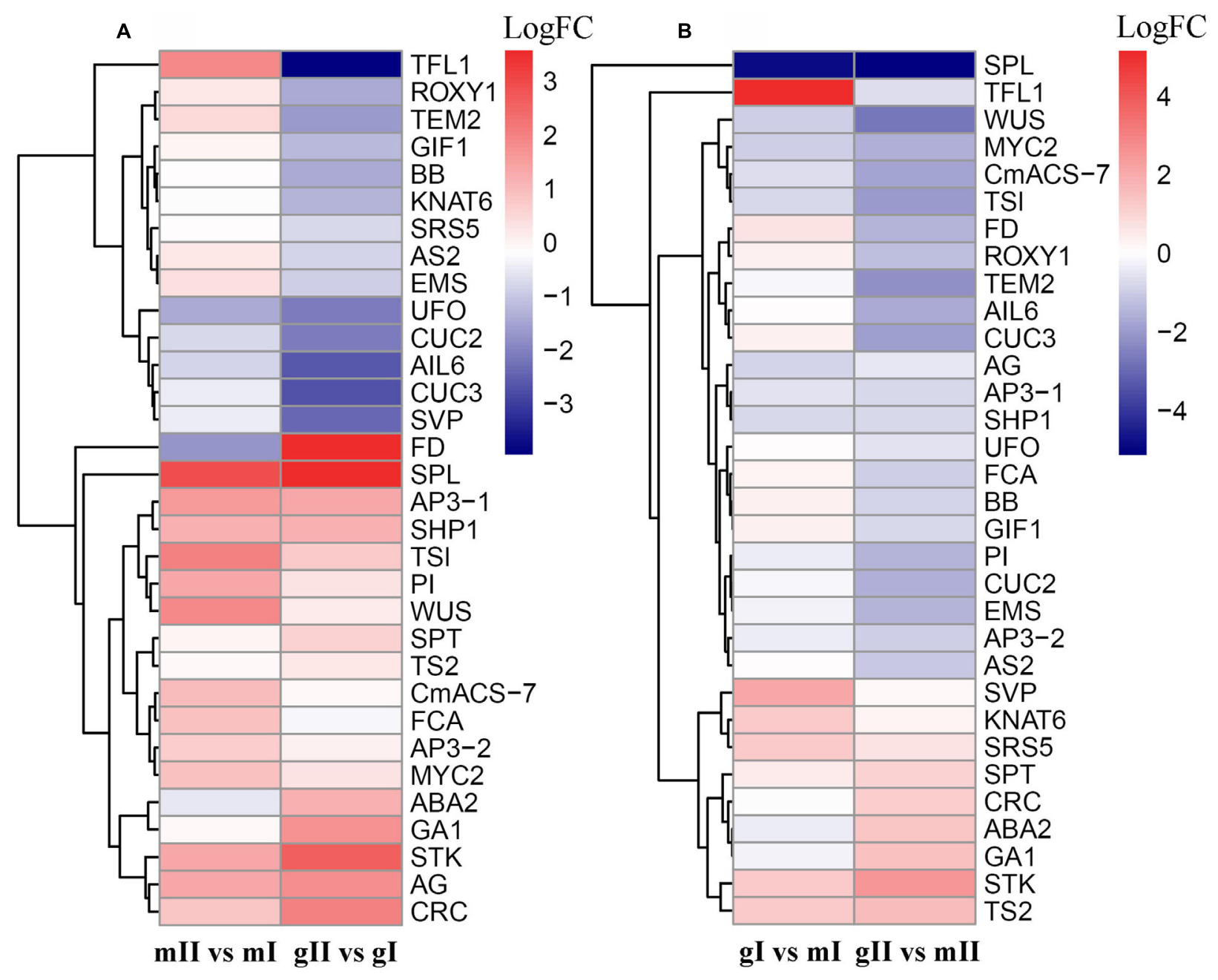

FIGURE 7 | Hierarchical clustering of differentially expressed genes involved in floral development in the pairwise mll vs. ml, gll vs. gl, gl vs. ml, and gll vs. $\mathbf{m l l}$ in $\mathbf{J}$. curcas. (A,B) Clustering of differentially expressed genes in the pairwise $\mathrm{mll}$ vs. $\mathrm{ml}$ and gll vs. gl, and in gl vs. $\mathrm{ml}$ and gll vs. $\mathrm{mll}$, respectively. $\mathrm{mll}$ vs. $\mathrm{ml}$, gll vs. gl, gl vs. ml, and gll vs. mll indicate the same pairs as shown in Figure 4.

which resulted in neutral flowers without pistils and stamens in gynoecious inflorescences (Figure 10).

\section{DISCUSSION}

\section{Floral Development Genes May Be Key Regulators in the Transition from Monoecious to Gynoecious Plants}

At initiation of inflorescence buds, female and male flower primordia are emerged in both gynoecious and monoecious plants. However, in gynoecious plants, the development of male flowers is aborted, and only female flowers can normally grow; whereas the development of both female and male flowers is normal in monoecious plants. Transcriptome analysis showed that differentially expressed genes in pairwise stage II vs. I in monoecious inflorescence are far less than ones in gynoecious
(Figure 4). This finding indicates that large physiological and biochemical changes occur in gynoecious inflorescences from stages I to II, in accord with the morphological change of male flower abortion. A large number of differentially expressed genes in pairwise gI vs. $\mathrm{mI}$ and gII vs. $\mathrm{mII}$ suggest that reproductive system differences between gynoecious and monoecious plants indeed result from inherent genetic variation.

In gynoecious plants, the abortion of male flowers was observed at stage II; however, the initiation of the process is expected to occur at stage I. Thus, the transition from stage I to stage II is a key period determining the sex expression of $J$. curcas. Genes differentially expressed at stage I contribute to the arrest of male flowers in gynoecious inflorescences. As shown in Supplementary Table S5, during the development of monoecious inflorescence from stage I to stage II, 11 of the 13 genes involved in the floral development were upregulated at transcriptional level. In contrast, the expression levels of 
10 genes involved in the floral development were downregulated during the development of gynoecious inflorescence from stage I to stage II, whereas the expression of these genes were not significantly changed in monoecious plants (Supplementary Table S5). These results suggest that different regulatory mechanisms of inflorescence development are present in monoecious and gynoecious Jatropha. The differentially expressed genes with similar expression patterns in pairwise gII vs. gI and gII vs. mII should be caused by male flower abortion, whereas ones with different expression patterns in pairwise gI vs. $\mathrm{mI}$ and gII vs. $\mathrm{mII}$, are more likely to contribute to the arrest of stamen primordium in gynoecious plants (Figure 7). Among the differentially expressed genes shown in Figure 7, KNAT6, MYC2, SRS5, SVP, TFL1, and TS2 were considered as strong candidate regulators of sex determination in J. curcas.

KNAT6 contributes to the maintenance of the shoot apical meristem and organ separation (Belles-Boix et al., 2006), and is an important regulator of Arabidopsis inflorescence architecture (Ragni et al., 2008). MYC2 is a master regulator modulating various JA-dependent signaling in plant development and defense, and controlling the crosstalk between JA and the other hormone signaling pathways (Kazan and Manners, 2013). SRS5 is a member of SHORT-INTERNODES/STYLISH (SHI/STY) family that may be involved in stamen and leaf development and flowering regulation (Staldal et al., 2012). SVP and TFL1 are inhibitors of the transition from vegetative growth to flowering (Hartmann et al., 2000). SVP also represses the biosynthesis of GA at the shoot apex in Arabidopsis (Andres et al., 2014). TS2 is a short-chain alcohol dehydrogenase that represses pistil primordium in maize tassels and both $t s 1$ and $t s 2$ mutants result in conversion from staminate to pistillate tassels (DeLong et al., 1993). Application of JA to developing tassels can rescue stamen development in ts 1 and ts 2 mutants (Acosta et al., 2009). Our results suggest that some floral development genes and phytohormones (mainly GA and JA) likely coordinate to modulate sex expression in J. curcas. It is worth mentioning that the expression levels of homologs of several well-known sex determination genes, such as CsACS in cucumber (Li et al., 2009), and CmACS and CmWIP1 in melon (Boualem et al., 2015), were not significantly different between monoecious and gynoecious plants, indicating that the mechanism of sex determination in cucumber and melon is different from that in J. curcas.

\section{GA Plays Important Roles in the Development of $J$. curcas Flowers}

GA20oxs and GA3oxs are key enzymes in GA biosynthesis, both being responsible for the conversion from $\mathrm{GA}_{12}$ to bioactive GAs (Yamaguchi, 2008). Expression of GA20ox2 and GA3ox1 are downregulated in gynoecious inflorescences (Figure 8; Supplementary Table S6), indicating that the GA biosynthesis is lower in gynoecious than in monoecious inflorescences. Furthermore $\mathrm{GA}_{3}$ treatment promoted perianth development in male flowers and repressed pistil development in female flowers to produce neutral flowers in gynoecious inflorescences (Figure 10). Our previous studies showed that $\mathrm{GA}_{3}$ treatment

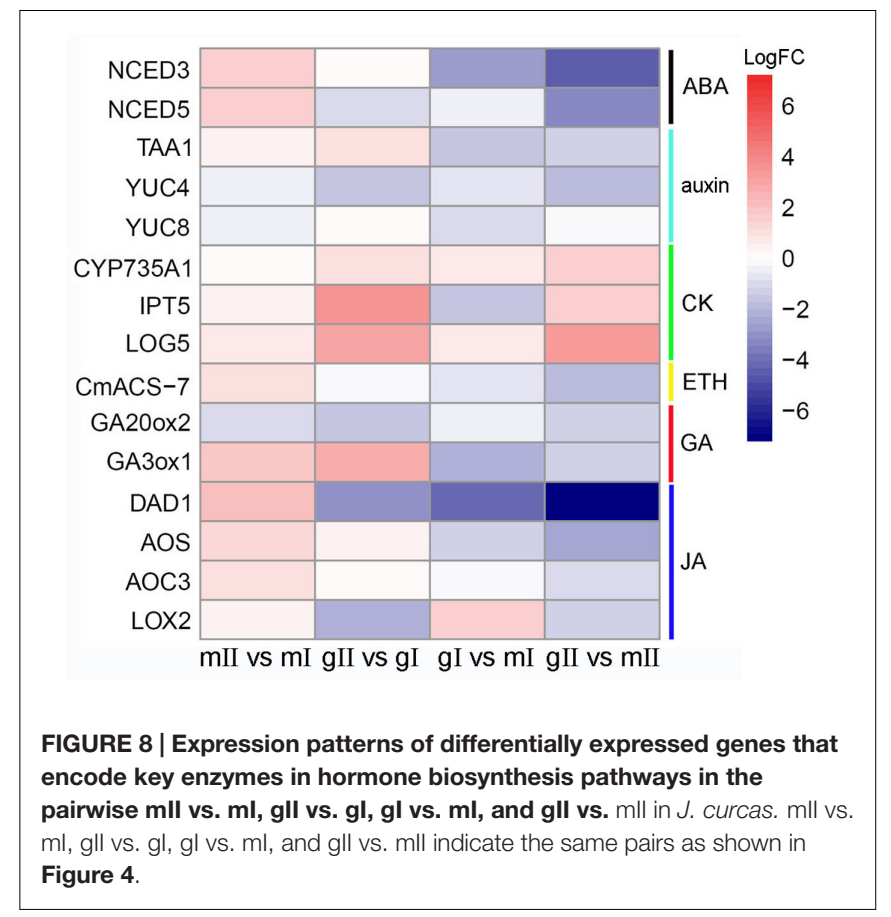

induced the emergence of neutral and bisexual flowers in monoecious plants ( $\mathrm{Pi}$ et al., 2013). These results suggest that GA plays essential roles in floral organ development in J. curcas. GA treatment did not resume the development of stamens in gynoecious male and female flowers, whereas GA promoted the development of stamens in monoecious female flowers to produce bisexual flowers, implying that the mechanisms controlling the arrest of stamen primordium between gynoecious and monoecious inflorescences are different. In maize, GA is a negative regulator in the development of stamen (Tanurdzic and Banks, 2004; Chen and Tan, 2015), but a positive regulator in Arabidopsis and rice (Cheng et al., 2004). Our results showed that GA has multiple functions in floral organ development in J. curcas, and also suggested that regulatory mechanisms controlling sex expression are different in various plant species.

\section{The Biosynthesis of Auxin Is Repressed in Gynoecious Inflorescences}

The TAA/YUC two-step pathway is the main auxin biosynthesis pathway (Zhao, 2013) and is widely present in plants (Yunde, 2010). TRYPTOPHAN AMINOTRANSFERASE OF ARABIDOPSIS 1 (TAA1) catalyzes the conversion from L-tryptophan (Trp) to indole-3-pyruvic acid (IPA) (Stepanova et al., 2008), and YUCCA (YUC) flavin-containing monooxygenases (FMOs) catalyze the oxidative decarboxylation of IPA to generate indole-3-acetic acid (IAA) (Mashiguchi et al., 2011). Both TAA1 and FMOs are rate-limiting enzymes in the regulation of auxin biosynthesis. The expression of TAA1, YUC4, and YUC8 was downregulated in pairwise gI vs. $\mathrm{mI}$ and gII vs. $\mathrm{mII}$, indicating that auxin biosynthesis is lower in gynoecious than in monoecious inflorescences. This finding is supported by 

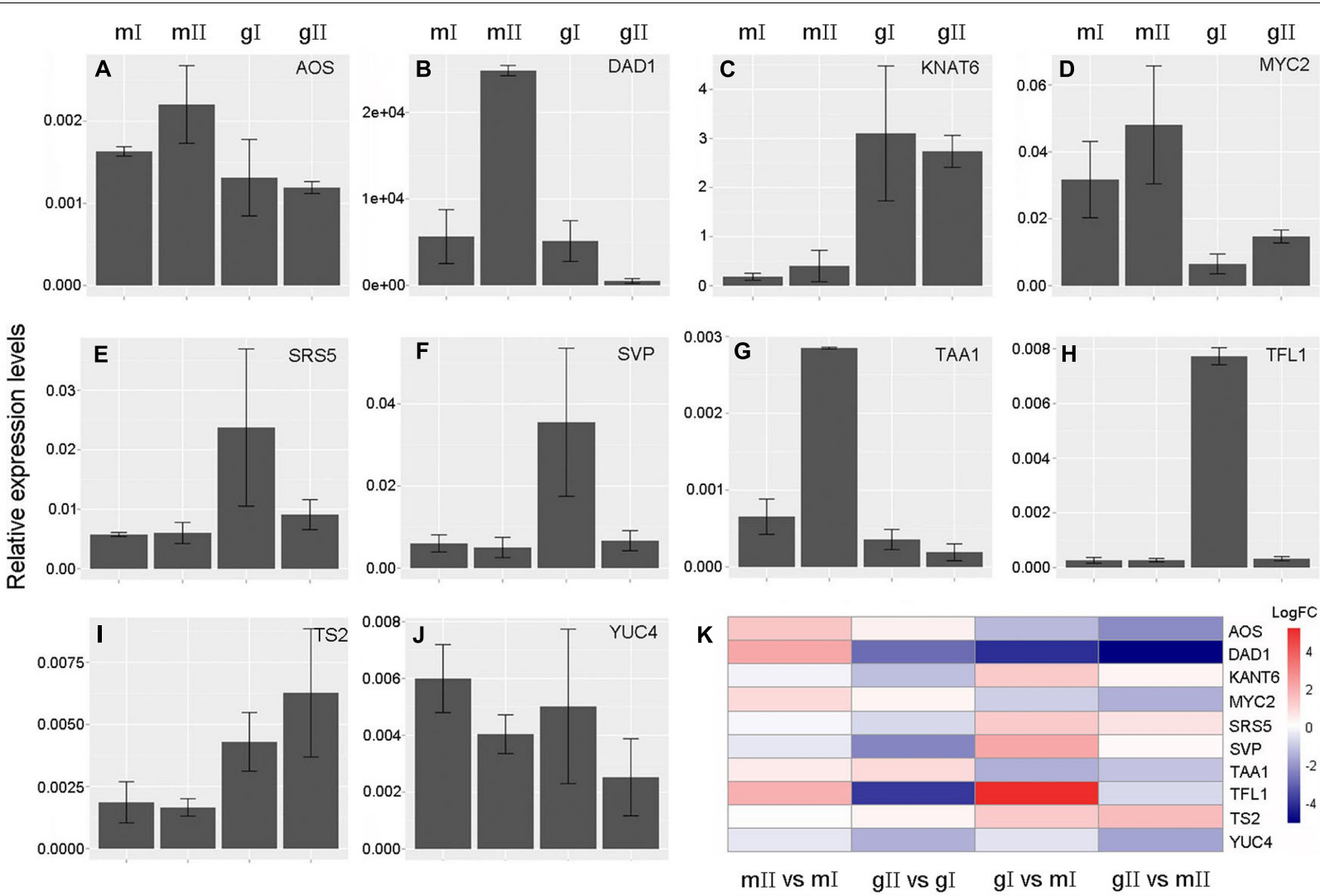

FIGURE 9 | Validation of expression profiles of the candidate genes involved in sex determination of J. curcas by real time qPCR. (A) ALLENE OXIDE SYNTHASE (AOS). (B) DEFECTIVE ANTHER DEHISCENCE 1 (DAD1). (C) KNOTTED1-LIKE HOMEOBOX GENE 6 (KNAT6). (D) MYC2. (E) SHI-RELATED SEQUENCE 5 (SRS5). (F) SHORT VEGETATIVE PHASE (SVP). (G) TRYPTOPHAN AMINOTRANSFERASE OF ARABIDOPSIS 1 (TAA1). (H) TERMINAL FLOWER 1 (TFL1). (I) TASSELSEED2 (TS2). (J) YUCCA 4 (YUC4). (K) Expression patterns of the candidate genes in four pairs. GAPDH was used as the internal reference. The mean was calculated from three biological replicates. Error bars show the SD $(n=3)$. $\mathrm{ml}$, mll, gl, and gll indicate the same samples as shown in Figure 3. mll vs. ml, gll vs. gl, gl vs. $\mathrm{ml}$, and gll vs. mll indicate the same pairs as in Figure 4. FC, fold change.

the observation that expressions of auxin responsive genes $B T B$ AND TAZ DOMAIN PROTEIN 2 (BT2), INDOLE-3-ACETIC ACID INDUCIBLE 14 (IAA14), IAA29, and SMALL AUXIN UP RNA 20 (SUR20), auxin transport genes PLEIOTROPIC DRUG RESISTANCE 9 (PPDR9), and PIN6 were down-regulated (Figure 8; Supplementary Table S6). In Arabidopsis and barley, high-temperature injury causes a specific decrease of endogenous auxin content in developing anthers, resulting in the arrest of pollen development, and exogenous application of IAA can completely reverse male sterility (Sakata et al., 2011), indicating that auxin is an important regulator in the development of male flowers. This result is in agreement with the finding that auxin biosynthesis is suppressed in gynoecious inflorescences (Figure 8), which might result in male flower abortion in gynoecious Jatropha.

In addition, auxin plays an indispensable role in regulating inflorescence branching in Arabidopsis (Teo et al., 2014). A lossof-function mutation in PIN-FORMED 1 (PIN1), an auxin carrier, abolishes the formation of an inflorescence meristem, resulting in naked inflorescence stems (Vernoux et al., 2000). In J. curcas, gynoecious inflorescences contain fewer branches than monoecious inflorescences (Figures 1C,F), which may be associated with the decrease of auxin biosynthesis in gynoecious inflorescence. This suggests that auxin may play a similar role in controlling inflorescence branching in J. curcas.

Two Arabidopsis cytochrome P450 monooxygenases, CYP79B2 and CYP79B3, catalyze the conversion of Trp to indole-3-acetaldoxime (IAOx), which is a common intermediate for the biosynthesis of IAA, 3-indolylmethyl-glucosinolate (IG) and camalexin (Hull et al., 2000; Mikkelsen et al., 2000; Zhao et al., 2002; Glawischnig et al., 2004). Overexpression of CYP79B2 increases IAA level leading to auxin overproduction phenotypes of transgenic plants (Zhao et al., 2001, 2002). Correspondingly, cyp79B2 cyp79B3 double mutants display IAAdeficient phenotypes in Arabidopsis (Zhao et al., 2002). Thus, IAOx is an important intermediate in auxin biosynthesis distinct from the TAA/YUC pathway (Zhao et al., 2002; Sugawara et al., 2009). However, IAOx has been detected only in Arabidopsis and related species, and the CYP79B family is also limited to Brassicaceae species, suggesting that the IAOx pathway is a Brassicaceae species-specific pathway in IAA biosynthesis (Mashiguchi et al., 2011). In J. curcas, the homologs CYP79B2 and 

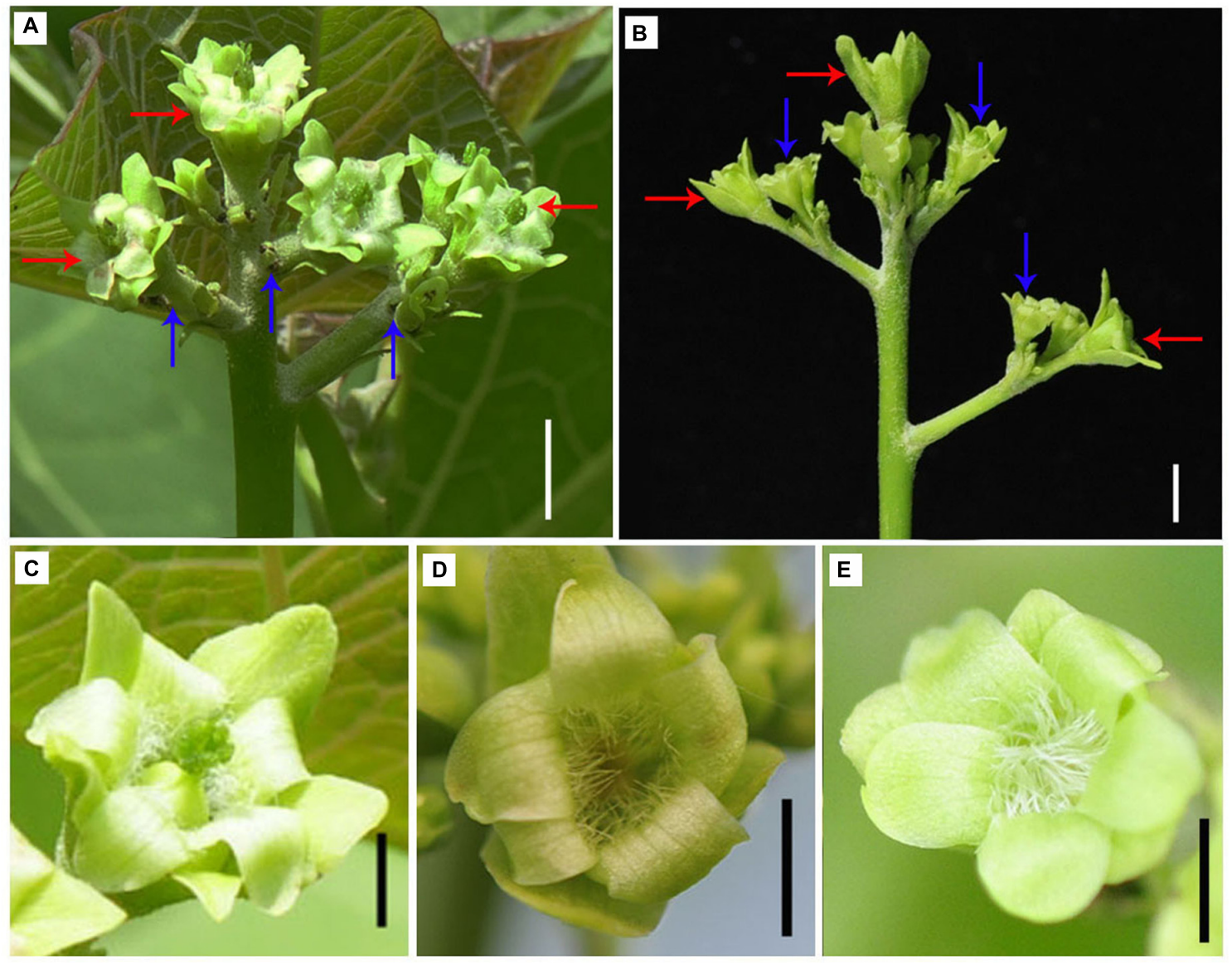

FIGURE 10 | Application of $\mathrm{GA}_{3}$ promotes perianth development in male flowers and prevents pistil development in female flowers in gynoecious inflorescences. (A) Gynoecious inflorescence without treatment. Red arrows indicate female flowers and blue arrows indicate aborted male flowers. (B) Gynoecious inflorescence with $\mathrm{GA}_{3}$ treatment. Red arrows indicate neutral flowers originated from female floral meristem, and blue arrows indicate neutral flowers originated from male floral meristem. (C) Female flower as shown and indicated with red arrows in (A). (D) Neutral flower originated from floral meristem generating female flowers after $\mathrm{GA}_{3}$ treatment as shown and indicated with red arrows in (B). (E) Neutral flower originated from floral meristem generating male flowers after $\mathrm{GA}_{3}$ treatment as shown and indicated with blue arrows in (B). Bar, $1.0 \mathrm{~cm}$.

CYP79B3 are upregulated in pairwise gI vs. $\mathrm{mI}$, indicating that IOAx biosynthesis is higher in gynoecious than in monoecious inflorescences (Supplementary Table S6); however, the expression of NITRILASES 1 (NIT1), NIT2, and NIT3, which are involved in the conversion from IAN to IAA, was not significantly changed (Supplementary Table S6). Moreover, the homolog CYP83B1, which converts IAOx to aci-nitro compounds in IG biosynthesis (Barlier et al., 2000; Bak et al., 2001), is upregulated in pairwise gI vs. mI and gII vs. mII (Supplementary Table S6). These results suggest that IAOx is more likely to be channeled into IG biosynthesis than into IAA, or even that IAOx is not involved in IAA biosynthesis, although an IAOx biosynthesis pathway is present in J. curcas.

\section{JA Signaling Pathway May Participate in the Abortion of Male Flowers}

Previous study showed that JA plays an essential role in regulating the development of inflorescences, flowers, and male organs, and JA biosynthesis and signaling pathway during reproductive development are conserved in Arabidopsis, tomato, and rice (Yuan and Zhang, 2015). In Arabidopsis, DEFECTIVE ANTHER DEHISCENCE 1 (DAD1) encodes a chloroplastic phospholipase A1 that catalyzes the initial step of JA biosynthesis, and the dad1 mutant displays defects in anther dehiscence, pollen maturation, and flower opening (Ishiguro et al., 2001). FATTY ACID DESATURASE 8 (FAD8), LIPOXYGENASE 2 (LOX2), ALLENE OXIDE SYNTHASE (AOS), and ALLENE OXIDE CYCLASE 3 (AOC3) are involved in JA biosynthesis in plastids (Turner et al., 2002). In J. curcas, the homologs of these genes are all downregulated in pairwise gI vs. $\mathrm{mI}$ or/and gII vs. $\mathrm{mII}$, implying that JA biosynthesis is lower in gynoecious than in monoecious inflorescences (Figure 8; Supplementary Table S6). The expression of FAD8, DAD1, AOS, and AOC3 is upregulated during inflorescence development from stage $I$ to II in monoecious plants, whereas $D A D 1$ and $L O X 2$ are downregulated in gynoecious plants (Figures 8 and 9; Supplementary Table S6). These results indicate that JA biosynthesis is also conserved in 
Jatropha, suggesting that the decrease of JA biosynthesis is likely to contribute to the abortion of male flowers in gynoecious plants. However, treatment with low concentration $(6 \mu \mathrm{M})$ of MeJA did not resume the development of stamens of male and female flowers in gynoecious plants (data not shown). Because Jatropha is extremely sensitive to MeJA, and treatment with $10 \mu \mathrm{M}$ of MeJA caused severe injury to inflorescences (data not shown), the concentration of MeJA used for treatment of Jatropha inflorescences will be optimized in future studies.

\section{Regulatory Networks Participate in the Transition from Monoecy to Gynoecy in J. curcas}

The phytohormones auxin, BR, CK, ETH, GA, and JA influence sex differentiation in flowering plants (Louis and Durand, 1978; Chailakhyan, 1979; Durand and Durand, 1984; Irish and Nelson, 1989; Perl-Treves, 1999). Our results showed that the expression of some key genes involved in ABA, auxin, $\mathrm{CK}, \mathrm{ETH}, \mathrm{GA}$, and JA biosynthesis pathways was significantly changed during inflorescence development and sex expression in J. curcas, suggesting that these hormones may participate in these processes. Thus, it is interesting to investigate how these hormones interact with one another to regulate the abortion of male flowers in gynoecious plants. However, only MYC2, a hub gene, was identified. MYC2 is a "master switch" in the crosstalk between JA and the other hormone signaling pathways, and has a wide range of functions in the regulation of developmental programs (Kazan and Manners, 2013). Both GA and JA promote MYC2 expression by a similar mechanism to modulate downstream gene expression (Kazan and Manners, 2013). Moreover, many reverse genetics experiments support that GA and JA play crucial roles in the development of stamens and pollen (Cheng et al., 2004; Yuan and Zhang, 2015). Based on

\section{REFERENCES}

Acosta, I. F., Laparra, H., Romero, S. P., Schmelz, E., Hamberg, M., Mottinger, J. P., et al. (2009). tasselseed 1 is a lipoxygenase affecting jasmonic acid signaling in sex determination of maize. Science 323, 262-265. doi: 10.1126/science.1164645

Ainsworth, C., Parker, J., and Buchanan-Wollaston, V. (1998). Sex determination in plants. Curr. Top. Dev. Biol. 38, 167-223. doi: 10.4161/psb.2.3.3728

Akagi, T., Henry, I. M., Tao, R., and Comai, L. (2014). A Y-chromosome-encoded small RNA acts as a sex determinant in persimmons. Science 346, 646-650. doi: 10.1126/science. 1257225

Andres, F., Porri, A., Torti, S., Mateos, J., Romera-Branchat, M., GarciaMartinez, J. L., et al. (2014). SHORT VEGETATIVE PHASE reduces gibberellin biosynthesis at the Arabidopsis shoot apex to regulate the floral transition. Proc. Natl. Acad. Sci. U.S.A. 111, E2760-E2769. doi: 10.1073/pnas.1409567111

Aryal, R., and Ming, R. (2014). Sex determination in flowering plants: papaya as a model system. Plant Sci. 21, 56-62. doi: 10.1016/j.plantsci.2013.10.018

Bak, S., Tax, F. E., Feldmann, K. A., Galbraith, D. W., and Feyereisen, R. (2001). CYP83B1, a cytochrome $\mathrm{P} 450$ at the metabolic branch point in auxin and indole glucosinolate biosynthesis in Arabidopsis. Plant Cell 13, 101-111. doi: 10.1105/tpc.13.1.101

Barlier, I., Kowalczyk, M., Marchant, A., Ljung, K., Bhalerao, R., Bennett, M., et al. (2000). The SUR2 gene of Arabidopsis thaliana encodes the cytochrome P450 CYP83B1, a modulator of auxin homeostasis. Proc. Natl. Acad. Sci. U.S.A. 97, 14819-14824. doi: 10.1073/pnas.260502697

Barrett, S. C. H. (2002). The evolution of plant sexual diversity. Nat. Rev. Genet. 3, 274-284. doi: $10.1038 / \mathrm{nrg} 776$ the results, we speculate that the arrest of stamen primordium, which may result from one or more gene mutation in monoecious Jatropha, causes the abortion of male flowers to generate gynoecious individuals, in which some floral development genes and plant hormone signaling pathways participate in.

\section{AUTHOR CONTRIBUTIONS}

Z-FX, M-SC, and B-ZP designed experiments. M-SC and Z-FX wrote the manuscript. M-SC, LN, and YD analyzed and interpreted sequencing data. QF, Y-BT, JM-H, JN, and M-LZ carried out experiments and reviewed the manuscript.

\section{FUNDING}

This work was supported by funding from the National Natural Science Foundation of China (31370595, 31300568, and 31500500), and the CAS 135 Program (XTBG-T02).

\section{ACKNOWLEDGMENTS}

The authors gratefully acknowledge the Central Laboratory of the Xishuangbanna Tropical Botanical Garden for providing the high-performance computing and other research facilities.

\section{SUPPLEMENTARY MATERIAL}

The Supplementary Material for this article can be found online at: http://journal.frontiersin.org/article/10.3389/fpls.2016.01953/ full\#supplementary-material

Bawa, K. S. (1980). Evolution of dioecy in flowering plants. Annu. Rev. Ecol. Syst. 11, 15-39. doi: 10.1146/annurev.es.11.110180.000311

Belles-Boix, E., Hamant, O., Witiak, S. M., Morin, H., Traas, J., and Pautot, V. (2006). KNAT6: an Arabidopsis homeobox gene involved in meristem activity and organ separation. Plant Cell 18, 1900-1907. doi: 10.1105/tpc.106. 041988

Bensen, R. J., Johal, G. S., Crane, V. C., Tossberg, J. T., Schnable, P. S., Meeley, R. B., et al. (1995). Cloning and characterization of the maize An1 gene. Plant Cell 7, 75-84. doi: 10.1105/tpc.7.1.75

Boualem, A., Fergany, M., Fernandez, R., Troadec, C., Martin, A., Morin, H., et al. (2008). A conserved mutation in an ethylene biosynthesis enzyme leads to andromonoecy in melons. Science 321, 836-838. doi: 10.1126/science. 1159023

Boualem, A., Troadec, C., Céline, C., Lemhemdi, A., Morin, H., Sari, M.-A., et al. (2015). A cucurbit androecy gene reveals how unisexual flowers develop and dioecy emerges. Science 350, 688-691. doi: 10.1126/science.aac8370

Chailakhyan, M. K. (1979). Genetic and hormonal regulation of growth, flowering, and sex expression in plants. Am. J. Bot. 66, 717-736. doi: 10.2307/ 2442417

Chen, M.-S., Pan, B.-Z., Wang, G.-J., Ni, J., Niu, L., and Xu, Z.-F. (2014). Analysis of the transcriptional responses in inflorescence buds of Jatropha curcas exposed to cytokinin treatment. BMC Plant Biol. 14:318. doi: 10.1186/s12870-0140318-Z

Chen, Y., and Tan, B.-C. (2015). New insight in the Gibberellin biosynthesis and signal transduction. Plant Signal. Behav. 10:e1000140. doi: 10.1080/15592324. 2014.1000140 
Cheng, H., Qin, L., Lee, S., Fu, X., Richards, D. E., Cao, D., et al. (2004). Gibberellin regulates Arabidopsis floral development via suppression of DELLA protein function. Development 131, 1055-1064. doi: 10.1242/dev.00992

Chuck, G. (2010). Molecular mechanisms of sex determination in monoecious and dioecious plants. Adv. Bot. Res. 54, 53-83. doi: 10.1016/S0065-2296(10)54002-3

Chuck, G., Meeley, R., Irish, E., Sakai, H., and Hake, S. (2007). The maize tasselseed 4 microRNA controls sex determination and meristem cell fate by targeting tasselseed6/indeterminate spikelet1. Nat. Genet. 39, 1517-1521. doi: 10.1038/ng.2007.20

Davidson, N. M., and Oshlack, A. (2014). Corset: enabling differential gene expression analysis for de novo assembled transcriptomes. Genome Biol. 15:410. doi: 10.1186/s13059-014-0410-6

Dellaporta, S. L., and Calderon-Urrea, A. (1993). Sex determination in flowering plants. Plant Cell 5, 1241-1251. doi: 10.1105/tpc.5.10.1241

Dellaporta, S. L., and Calderon-Urrea, A. (1994). The sex determination process in maize. Science 266, 1501-1505. doi: 10.1126/science.7985019

DeLong, A., Calderon-Urrea, A., and Dellaporta, S. L. (1993). Sex determination gene TASSELSEED2 of maize encodes a short-chain alcohol dehydrogenase required for stage-specific floral organ abortion. Cell 74, 757-768. doi: 10.1016/ 0092-8674(93)90522-R

Diggle, P. K., Di Stilio, V. S., Gschwend, A. R., Golenberg, E. M., Moore, R. C., Russell, J. R. W., et al. (2011). Multiple developmental processes underlie sex differentiation in angiosperms. Trends Genet. 27, 368-376. doi: 10.1016/j.tig. 2011.05.003

Durand, R., and Durand, B. (1984). Sexual differentiation in higher plants. Physiol. Plant. 60, 267-274. doi: 10.1111/j.1399-3054.1984.tb06061.x

Fairless, D. (2007). Biofuel: the little shrub that could-maybe. Nature 449, 652-655. doi: $10.1038 / 449652 a$

Field, D. L., Pickup, M., and Barrett, S. C. H. (2013). Comparative analyses of sex-ratio variation in dioecious flowering plants. Evolution 67, 661-672. doi: 10.1111/evo.12001

Fröschle, M., Horn, H., and Spring, O. (2016). Effects of the cytokinins 6benzyladenine and forchlorfenuron on fruit-, seed- and yield parameters according to developmental stages of flowers of the biofuel plant Jatropha curcas L. (Euphorbiaceae). Plant Growth Regul. doi: 10.1007/s10725-0160206-7 [Epub ahead of print].

Glawischnig, E., Hansen, B. G., Olsen, C. E., and Halkier, B. A. (2004). Camalexin is synthesized from indole-3-acetaldoxime, a key branching point between primary and secondary metabolism in Arabidopsis. Proc. Natl. Acad. Sci. U.S.A. 101, 8245-8250. doi: 10.1073/pnas.0305876101

Golenberg, E. M., and West, N. W. (2013). Hormonal interactions and gene regulation can link monoecy and environmental plasticity to the evolution of dioecy in plants. Am. J. Bot. 100, 1022-1037. doi: 10.3732/ajb. 1200544

Grabherr, M. G., Haas, B. J., Yassour, M., Levin, J. Z., Thompson, D. A., Amit, I., et al. (2011). Full-length transcriptome assembly from RNA-Seq data without a reference genome. Nat. Biotechnol. 29, 644-652. doi: 10.1038/nbt.1883

Haas, B. J., Papanicolaou, A., Yassour, M., Grabherr, M., Blood, P. D., Bowden, J., et al. (2013). De novo transcript sequence reconstruction from RNA-seq using the Trinity platform for reference generation and analysis. Nat. Protoc. 8, 1494-1512. doi: 10.1038/nprot.2013.084

Hartmann, U., Hohmann, S., Nettesheim, K., Wisman, E., Saedler, H., and Huijser, P. (2000). Molecular cloning of SVP: a negative regulator of the floral transition in Arabidopsis. Plant J. 21, 351-360. doi: 10.1046/j.1365-313x.2000. 00682.x

Hartwig, T., Chuck, G. S., Fujioka, S., Klempien, A., Weizbauer, R., Potluri, D. P., et al. (2011). Brassinosteroid control of sex determination in maize. Proc. Natl. Acad. Sci. U.S.A. 108, 19814-19819. doi: 10.1073/pnas.1108359108

Huang, D. W., Sherman, B. T., and Lempicki, R. A. (2009). Systematic and integrative analysis of large gene lists using DAVID bioinformatics resources. Nat. Protoc. 4, 44-57. doi: 10.1038/nprot.2008.211

Hull, A. K., Vij, R., and Celenza, J. L. (2000). Arabidopsis cytochrome P450s that catalyze the first step of tryptophan-dependent indole-3-acetic acid biosynthesis. Proc. Natl. Acad. Sci. U.S.A. 97, 2379-2384. doi: 10.1073/pnas. 040569997

Irish, E. E., and Nelson, T. (1989). Sex determination in monoecious and dioecious plants. Plant Cell 1, 737-744. doi: 10.1105/tpc.1.8.737
Ishiguro, S., Kawai-Oda, A., Ueda, J., Nishida, I., and Okada, K. (2001). The DEFECTIVE IN ANTHER DEHISCIENCE gene encodes a novel phospholipase A1 catalyzing the initial step of jasmonic acid biosynthesis, which synchronizes pollen maturation, anther dehiscence, and flower opening in Arabidopsis. Plant Cell 13, 2191-2209. doi: 10.1105/tpc. 010192

Kamachi, S. I., Sekimoto, H., Kondo, N., and Sakai, S. (1997). Cloning of a cDNA for a 1-aminocyclopropane-1-carboxylate synthase that is expressed during development of female flowers at the apices of Cucumis sativus L. Plant Cell Physiol. 38, 1197-1206. doi: 10.1093/oxfordjournals.pcp.a029106

Kazan, K., and Manners, J. M. (2013). MYC2: the master in action. Mol. Plant 6, 686-703. doi: $10.1093 / \mathrm{mp} / \mathrm{sss} 128$

Kenigsbuch, D., and Cohen, Y. (1990). The inheritance of gynoecy in muskmelon. Genome 33, 317-320. doi: 10.1139/g90-049

Korpelainen, H. (1998). Labile sex expression in plants. Biol. Rev. 73, 157-180. doi: 10.1111/j.1469-185X.1997.tb00028.x

Langmead, B., Trapnell, C., Pop, M., and Salzberg, S. L. (2009). Ultrafast and memory-efficient alignment of short DNA sequences to the human genome. Genome Biol. 10, R25-R25. doi: 10.1186/gb-2009-10-3-r25

Li, Z., Huang, S., Liu, S., Pan, J., Zhang, Z., Tao, Q., et al. (2009). Molecular isolation of the $\mathrm{M}$ gene suggests that a conserved-residue conversion induces the formation of bisexual flowers in cucumber plants. Genetics 182, 1381-1385. doi: 10.1534/genetics.109.104737

Louis, J. P., and Durand, B. (1978). Studies with the dioecious angiosperm Mercurialis annua L. $(2 \mathrm{n}=16)$ : correlation between genic and cytoplasmic male sterility, sex segregation and feminizing hormones (cytokinins). Mol. Gen. Genet. 165, 309-322. doi: 10.1007/bf00332532

Martin, A., Troadec, C., Boualem, A., Rajab, M., Fernandez, R., Morin, H., et al. (2009). A transposon-induced epigenetic change leads to sex determination in melon. Nature 461, 1135-1138. doi: 10.1038/nature08498

Mashiguchi, K., Tanaka, K., Sakai, T., Sugawara, S., Kawaide, H., Natsume, M., et al. (2011). The main auxin biosynthesis pathway in Arabidopsis. Proc. Natl. Acad. Sci. U.S.A. 108, 18512-18517. doi: 10.1073/pnas.1108434108

Mibus, H., and Tatlioglu, T. (2004). Molecular characterization and isolation of the F/f gene for femaleness in cucumber (Cucumis sativus L.). Theor. Appl. Genet. 109, 1669-1676. doi: 10.1007/s00122-004-1793-7

Mikkelsen, M. D., Hansen, C. H., Wittstock, U., and Halkier, B. A. (2000). Cytochrome P450 CYP79B2 from Arabidopsis catalyzes the conversion of tryptophan to indole-3-acetaldoxime, a precursor of indole glucosinolates and indole-3-acetic acid. J. Biol. Chem. 275, 33712-33717. doi: 10.1074/jbc. M001667200

Pan, B.-Z., and Xu, Z.-F. (2011). Benzyladenine treatment significantly increases the seed yield of the biofuel plant Jatropha curcas. J. Plant Growth Regul. 30, 166-174. doi: 10.1007/s00344-010-9179-3

Perl-Treves, R. (1999). "Male to female conversion along the cucumber shoot: approaches to studying sex genes and floral development in Cucumis sativus," in Sex determination in plants, ed. C. C. Ainsworth (Oxford: Bios Press), $189-286$.

Pi, X.-J., Pan, B.-Z., and Xu, Z.-F. (2013). Induction of bisexual flowers by gibberellin in monoecious biofuel plant Jatropha curcas (Euphorbiaceae). Plant Divers. Resour. 35, 26-32.

Pierce, L. K., and Wehner, T. C. (1990). Review of genes and linkage groups in cucumber. HortScience 25, 605-615.

Piferrer, F. (2013). Epigenetics of sex determination and gonadogenesis. Dev. Dyn. 242, 360-370. doi: 10.1002/dvdy.23924

Poole, C. F., and Grimball, P. C. (1939). Inheritance of new sex forms in Cucumis melo L. J. Hered. 30, 21-25.

Ragni, L., Belles-Boix, E., Günl, M., and Pautot, V. (2008). Interaction of KNAT6 and KNAT2 with BREVIPEDICELLUS and PENNYWISE in Arabidopsis inflorescences. Plant Cell 20, 888-900. doi: 10.1105/tpc.108.058230

Rincon-Rabanales, M., Vargas-Lopez, L. I., Adriano-Anaya, L., VazquezOvando, A., Salvador-Figueroa, M., and Ovando-Medina, I. (2016). Reproductive biology of the biofuel plant Jatropha curcas in its center of origin. PeerJ 4:e1819. doi: 10.7717/peerj.1819

Robinson, M. D., McCarthy, D. J., and Smyth, G. K. (2010). edgeR: a Bioconductor package for differential expression analysis of digital gene expression data. Bioinformatics 26, 139-140. doi: 10.1093/bioinformatics/btp616 
Sakata, T., Oshino, T., Miura, S., Tomabechi, M., Tsunaga, Y., Higashitani, N., et al. (2011). Auxins reverse plant male sterility caused by high temperatures. Proc. Natl. Acad. Sci. U.S.A. 107, 8569-8574. doi: 10.1073/pnas.10008 69107

Sato, S., Hirakawa, H., Isobe, S., Fukai, E., Watanabe, A., Kato, M., et al. (2011). Sequence analysis of the genome of an oil-bearing tree, Jatropha curcas L. DNA Res. 18, 65-76. doi: 10.1093/dnares/dsq030

Staldal, V., Cierlik, I., Chen, S., Landberg, K., Baylis, T., Myrenas, M., et al. (2012). The Arabidopsis thaliana transcriptional activator STYLISH1 regulates genes affecting stamen development, cell expansion and timing of flowering. Plant Mol. Biol. 78, 545-559. doi: 10.1007/s11103-012-9888-z

Stepanova, A. N., Robertson-Hoyt, J., Yun, J., Benavente, L. M., Xie, D. Y., Dolezal, K., et al. (2008). TAA1-mediated auxin biosynthesis is essential for hormone crosstalk and plant development. Cell 133, 177-191. doi: 10.1016/j. cell.2008.01.047

Sugawara, S., Hishiyama, S., Jikumaru, Y., Hanada, A., Nishimura, T., Koshiba, T., et al. (2009). Biochemical analyses of indole-3-acetaldoxime-dependent auxin biosynthesis in Arabidopsis. Proc. Natl. Acad. Sci. U.S.A. 106, 5430-5435. doi: 10.1073/pnas.0811226106

Tanurdzic, M., and Banks, J. A. (2004). Sex-determining mechanisms in land plants. Plant Cell 16(Suppl. 1), S61-S71. doi: 10.1105/tpc. 016667

Teo, Z. W. N., Song, S., Wang, Y.-Q., Liu, J., and Yu, H. (2014). New insights into the regulation of inflorescence architecture. Trends Plant Sci. 19, 158-165. doi: 10.1016/j.tplants.2013.11.001

Thomson, J. D., and Barrett, S. C. H. (1981). Selection for outcrossing, sexual selection, and the evolution of dioecy in plants. Am. Nat. 118, 443-449. doi: $10.1086 / 283837$

Turner, J. G., Ellis, C., and Devoto, A. (2002). The jasmonate signal pathway. Plant Cell 14(Suppl. 1), S153-S164. doi: 10.1105/tpc.000679

Vernoux, T., Kronenberger, J., Grandjean, O., Laufs, P., and Traas, J. (2000). PINFORMED 1 regulates cell fate at the periphery of the shoot apical meristem. Development 127, 5157-5165.

Wang, D. H., Li, F., Duan, Q. H., Han, T., Xu, Z. H., and Bai, S. N. (2010). Ethylene perception is involved in female cucumber flower development. Plant J. 61, 862-872. doi: 10.1111/j.1365-313X.2009.04114.x

Yamaguchi, S. (2008). Gibberellin metabolism and its regulation. Annu. Rev. Plant Biol. 59, 225-251. doi: 10.1146/annurev.arplant.59.032607. 092804
Yamasaki, S., Fujii, N., and Takahashi, H. (2005). Hormonal regulation of sex expression in plants. Vitam. Horm. 72, 79-110. doi: 10.1016/S0083-6729(05) 72003-3

Yampolsky, C., and Yampolsky, H. (1922). Distribution of sex forms in the phanerogamic flora. Bibl. Genet. 3, 1-62.

Yuan, Z., and Zhang, D. (2015). Roles of jasmonate signalling in plant inflorescence and flower development. Curr. Opin. Plant Biol. 27, 44-51. doi: 10.1016/j.pbi. 2015.05.024

Yunde, Z. (2010). Auxin biosynthesis and its role in plant development. Annu. Rev. Plant Biol. 61, 49-64. doi: 10.1146/annurev-arplant-042809-112308

Zhang, J., Boualem, A., Bendahmane, A., and Ming, R. (2014). Genomics of sex determination. Curr. Opin. Plant Biol. 18, 110-116. doi: 10.1016/j.pbi.2014.02. 012

Zhang, M., Zhan, F., Sun, H., Gong, X., Fei, Z., and Gao, S. (2014). "Fastq_clean: an optimized pipeline to clean the Illumina sequencing data with quality control," in Proceedings of the IEEE International Conference on Bioinformatics and Biomedicine (BIBM), Belfast.

Zhao, Y. (2013). Auxin biosynthesis: a simple two-step pathway converts tryptophan to indole-3-acetic acid in plants. Mol. Plant 5, 334-338. doi: 10. 1093/mp/ssr104

Zhao, Y., Christensen, S. K., Fankhauser, C., Cashman, J. R., Cohen, J. D., Weigel, D., et al. (2001). A role for flavin monooxygenase-like enzymes in auxin biosynthesis. Science 291, 306-309. doi: 10.1126/science.291.5502.306

Zhao, Y., Hull, A. K., Gupta, N. R., Goss, K. A., Alonso, J., Ecker, J. R., et al. (2002). Trp-dependent auxin biosynthesis in Arabidopsis: involvement of cytochrome P450s CYP79B2 and CYP79B3. Genes Dev. 16, 3100-3112. doi: 10.1101/gad. 1035402

Conflict of Interest Statement: The authors declare that the research was conducted in the absence of any commercial or financial relationships that could be construed as a potential conflict of interest.

Copyright (c) 2017 Chen, Pan, Fu, Tao, Martínez-Herrera, Niu, Ni, Dong, Zhao and $X u$. This is an open-access article distributed under the terms of the Creative Commons Attribution License (CC BY). The use, distribution or reproduction in other forums is permitted, provided the original author(s) or licensor are credited and that the original publication in this journal is cited, in accordance with accepted academic practice. No use, distribution or reproduction is permitted which does not comply with these terms. 